\title{
Perancangan produk interior modular berbahan upcycling kayu bekas palet
}

\author{
Venlista Suprapto, ${ }^{1}$ Yusita Kusumarini, ${ }^{2 *}$ Frenky Tanaya $^{3}$ \\ ${ }^{1,2}$ Program Studi Desain Interior, Universitas Kristen Petra, Surabaya, Indonesia \\ ${ }^{3}$ Woodstock, Surabaya, Indonesia
}

\begin{abstract}
The flow of containers in the terminals of the Port of Tanjung Perak Surabaya has increased. The increased container flow has an impact on the pilling up of ex-wood pallets and if this left continuously it become city trash. Even though ex-wood pallets have the characteristics and potential to be developed, for that we have do upcycling. In addition, people who live in narrow homes usually discarded or replaced their old interior products because they do not fit into the new space. Therefore, people need a modular interior product that can be assembled from scratch, and can be arranged according to the needs and desires of the user, by doing upcycling to reduce the pilling up of ex-wood pallets. The design aims to knowing the characteristics and potential of ex-wood pallets, then reused into modular interior products with modules that accordance with their characteristic. The modules are connected using connectors, which can be assembled according to the user's needs. Design thinking methods consisting of inspiration, ideation, and implementasion are carried out in this design process. The results of this design are modules and connectors that can be assembled into 12 types of products, media promotion, and booth design. This design proved that ex-wood pallets have characteristics and potential that can be develop by upcycling into modules in accordance with the characteristics of used wood pallets that can be assembled using connector into a variety of modular interior products according to the needs and desires of the user.
\end{abstract}

Key words: ex-wood pallets, upcycling, modular interior products

\begin{abstract}
Abstrak
Arus peti kemas di terminal-terminal wilayah Pelabuhan Tanjung Perak Surabaya meningkat. Peningkatan arus peti kemas berdampak pada penumpukan kayu bekas palet dan jika dibiarkan akan menjadi sampah kota. Padahal kayu bekas palet memiliki karakteristik dan potensi untuk dikembangkan, untuk itu akan dilakukan upcycling. Di sisi lain masyarakat yang tinggal pada hunian sempit sering kali membuang atau mengganti produk interior yang lama karena tidak cocok dengan ruang yang baru. Maka dari itu diperlukan produk interior modular yang dapat dirakit dari nol, dan bisa disusun sesuai dengan kebutuhan dan keinginan pengguna, dengan melakukan upcycling untuk mengurangi penumpukan kayu bekas palet. Perancangan ini bertujuan untuk mengetahui karakteristik dan potensi dari kayu bekas palet, kemudian digunakan kembali menjadi produk interior modular dengan bentuk modul sesuai karakteristiknya. Modul-modul tersebut disambungkan menggunakan konektor, yang dapat dirakit sesuai keinginan pengguna. Metode design thinking yang terdiri dari tahap inspiration, ideation, dan implementation dilakukan dalam proses perancangan ini. Hasil perancangan ini berupa modulmodul dan konektor yang dapat dirakit menjadi 12 macam produk, brand perusahaan, media promosi dan desain booth. Perancangan ini membuktikan bahwa kayu bekas palet memiliki karakteristik dan potensi yang dapat dikembangkan dengan cara upcycling, menjadi modul-modul dengan bentuk sesuai karakteristik dari kayu bekas palet yang dapat dirakit menggunakan sambungan konektor menjadi beberapa macam produk interior modular sesuai kebutuhan dan keinginan pengguna.
\end{abstract}

Kata kunci: kayu bekas palet, upcycling, produk interior modular

\section{Pendahuluan}

Pelabuhan Tanjung Perak di Surabaya yang menjadi pusat ekspor impor barang dagang membuat di kota Surabaya memiliki jumlah peti kemas yang berlimpah. Berdasarkan data yang dihimpun PT Pelabuhan Indonesia III, arus peti kemas di terminalterminal wilayah Pelabuhan Tanjung Perak Surabaya

\footnotetext{
* Corresponding author Tel : +62-812-316-8156 ; e-mail : yusita@petra.ac.id
} 
meningkat, dari tahun 2018 yang berjumlah 16.310 boks menjadi 35.550 boks pada tahun 2019. Gambar 1 memperlihatkan arus peti kemas di Pelabuhan Tanjung Perak Surabaya (Antonius, 2019). Peningkatan arus peti kemas tersebut berdampak pada penumpukan kayu bekas palet di Surabaya yang juga bertambah. Penumpukan kayu bekas palet jika dibiarkan akan menyebabkan sampah kota.

Kayu palet digunakan sebagai bahan pengemas karena memiliki karakter kering, anti rayap serta resisten terhadap benturan sehingga kerusakan akibat kontak keras akan lebih minim terjadi (Kania, 2018). Sayangnya kayu bekas palet ini hanya satu kali pakai, yang dapat menambah jumlah limbah perkotaan. Padahal kayu bekas palet memiliki karakteristik dan potensi yang dapat dikembangkan, untuk itu dilakukan upcycling.

Upcycling adalah bentuk daur ulang yang mengubah limbah menjadi bahan atau produk dengan berkualitas lebih tinggi (Sinai, 2017). Kayu limbah dapat pula didaur ulang menjadi produk yang lebih berkualitas (Prasetya, 2016), termasuk limbah kayu bekas peti kemas/kayu palet (Arya PN, Azhar, Reza, Pratama, \& Nugraha, 2020; Beatrice, Setiadi, Saraswati, \& MT, 2018)

Kayu bekas palet akan di-upcycle dengan cara melihat potensi dari karakteristik kayu tersebut dan di-redesign, untuk dimanfaatkan menjadi produk interior modular. Karena pada hunian sempit atau ruang terbatas seringkali mengalami kesulitan dalam memilih dan menata produk interior (Juanda, 2019). Banyak orang yang ketika pindah ke rumah baru, produk interior yang lama sering kali dibuang atau diganti karena tidak cocok dengan ruang yang baru. Dengan memilih produk interior yang menyesuaikan kebutuhan dan dapat memaksimalkan lahan. Produk interior yang praktis dan bersifat modular dapat menjadi solusi dan sangat diminati masyarakat (Ririn, 2017). Untuk lahan yang sempit, konsep produk interior yang praktis dan modular dapat menjadi solusi untuk menjawab kebutuhan.

Produk interior modular dapat menjadi solusi untuk memaksimalkan lahan sempit dan menjawab kebutuhan pengguna (Kania, 2018). Karena produk interior modular menawarkan keleluasaan pada desain dan fungsinya (Ririn, 2017). Dimana desain dari produk interior dapat dikreasikan oleh pengguna sesuai kebutuhan dari pengguna. Produk interior modular merupakan produk yang dirakit dari nol, dapat disesuaikan dengan kebutuhan pengguna dan dibuat dengan bahan pilihan pengguna (Sinai, 2017). Sesuai dengan namanya, produk interior modular tersedia dalam bentuk modul atau bagian terpisah yang dapat ditambah ataupun dikurangi sesuai kebutuhan pengguna. Sehingga perancangan produk interior modular diharapkan dapat menjadi salah satu produk interior yang menjawab kebutuhan.

Maka dari itu diperlukan kreativitas untuk mengolah kayu bekas palet ini. "Perancangan produk interior modular berbahan upcycling kayu bekas palet” yang bertujuan untuk mengetahui karakteristik dan potensi kayu bekas palet sebagai material baru, dan dirancang menjadi produk interior modular. Perancangan ini berkontribusi mengurangi limbah dari sektor industri menjadi limbah yang terolah, dengan cara mendaur ulang kayu bekas palet menjadi produk interior modular yang dapat disesuaikan dengan kebutuhan pengguna.

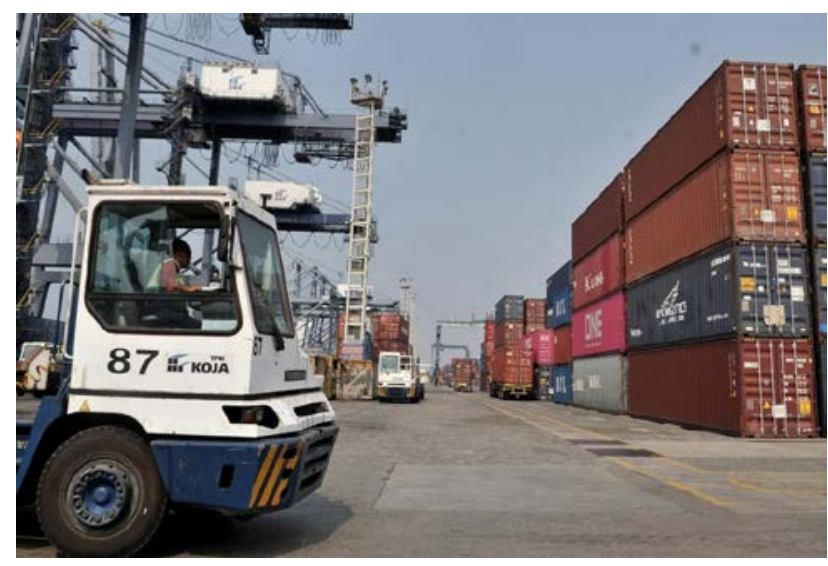

Gambar 1. Arus peti kemas Pelabuhan Tanjung Perak Surabaya (Sumber: Antonius, 2019).

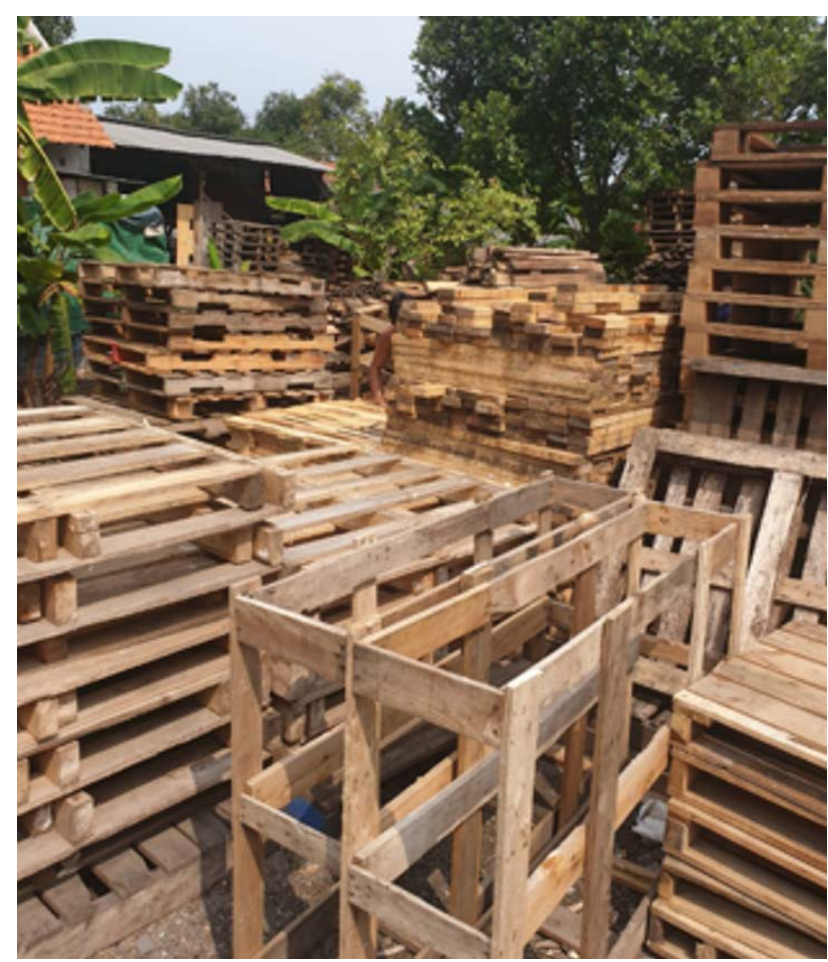

Gambar 2. Tumpukan kayu bekas palet 


\section{Bahan dan metode}

Metode desain yang digunakan dalam perancangan produk interior modular dengan upcycling kayu bekas peti kemas ini menggunakan design thinking milik d'school Paris 2009, yang dipopulerkan oleh Tim Brown, yaitu inspiration, ideation, dan implementation (Gambar 3).

Inspiration merupakan tahap awal untuk mengetahui permasalahan, mencari solusi dan mengumpulkan data terkait produk yang akan dirancang yang dilakukan dengan 3 tahapan, yaitu understand, observe, dan Point of View (POV). Understand merupakan tahapan mendekati, memahami, dan mengumpulkan data terkait permasalahan yang perlu diselesaikan secara desain. Pemahaman dilakukan dengan eksplorasi data terkait melalui data literatur dan tinjauan lapangan. observasi adalah tahapan pendalaman pemahaman berkaitan dengan data pendukung perancangan produk interior modular dari kayu bekas peti kemas. Pada perancangan ini digunakan beberapa metode untuk lebih mendalami dan memahami topik perancangan. Point of view merupakan pengelompokan data. Dimana data-data yang diperoleh, disandingkan satu sama lain hingga ditemukan korelasinya. Menentukan permasalahan. Pada perancangan ini digunakan beberapa metode untuk mengkorelasikan temuan data pada tahap-tahap sebelumnya, seperti programming, dan branding.

Ideation merupakan tahap untuk pengolahan ideide untuk memberikan solusi desain terkait permasalahan yang ada. Yang dilakukan dengan 3 tahapan, yaitu ideate, prototype, dan test. Ideate

\section{THE DESICN THINKING PROCESS}

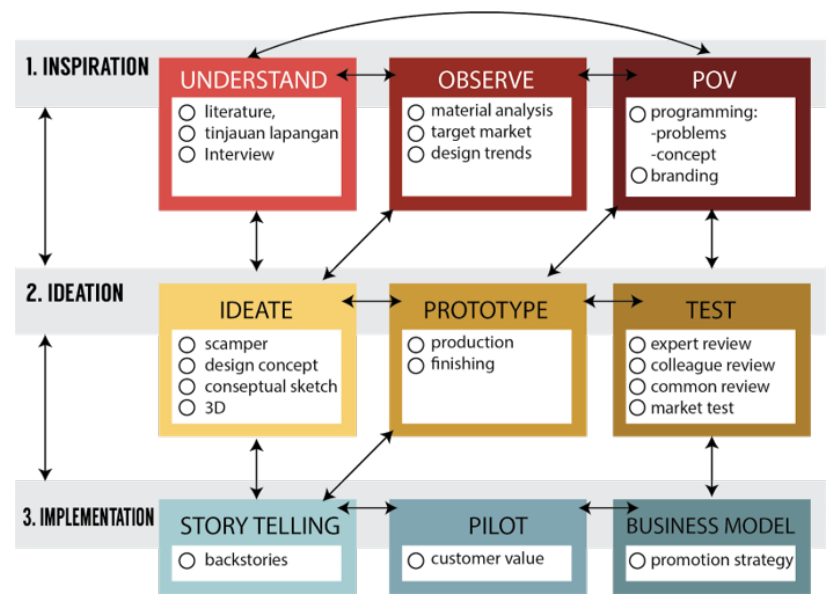

Gambar 3. Bagan Rencana Tahapan Perancangan adalah tahapan pembuatan ide-ide secara yang akan menjadi landasan untuk membuat solusi-solusi yang inovatif. Dengan menggunakan beberapa metode untuk menghasilkan ide-ide yang banyak, seperti design concept, SCAMPER, Conceptual sketches, Schematic design, 3D modeling \& rendering. Tahap prototype adalah tahapan pembuatan model-model hasil transformasi dari ide-ide abstrak menjadi bentuk yang lebih konkrit, yang dapat dilihat dan dirasakan, yang ditujukan agar dapat mengetahui kekurangan ataupun kelebihan dari model yang dibuat. Tahap test adalah tahapan untuk menguji dan mendapatkan umpan balik dari khalayak umum sehingga dapat mengetahui kelebihan dan kekurangan dari produk yang dibuat dari banyak sudut pandang, yang mana hasil evaluasi tersebut dapat digunakan untuk melakukan pembaruan-pembaruan yang dapat meningkatkan kualitas produk.

Implementation merupakan tahap akhir perancangan yang dilakukan dengan 3 tahapan yaitu storytelling, pilot, dan bussiness model. Story telling adalah tahapan pembuatan cerita dari perancangan yang dihasilkan, latar belakang, tujuan, manfaat perancangan, dan kontribusinya yang dapat dirasakan oleh khalayak umum yang melihat hasil perancangan ini. pilot adalah tahapan pembuatan kebaruan yang belum pernah dilakukan sebelumnya, dan memperkenalkan branding dan value produk kepada masyarakat/ pengguna. Business model adalah tahapan pembuatan sebuah model bisnis berkelanjutan yang tidak hanya berorientasi pada aspek ekonomi saja tetapi juga bisa ke aspek sosial. Membuat kebutuhan promosi produk seperti brosur, video, sosial media

Pada tahap awal perancangan dilaksanakan studi literatur terhadap beberapa istilah atau aspek, yaitu produk modular, upcycling, ergonomi dan antropometri, dan kayu palet. Hasil studi literatur tersebut diuraikan pada beberapa bagian di bawah ini. Produk interior modular merupakan produk yang dirakit dari nol, dan dapat disesuaikan dengan kebutuhan dan dibuat dengan bahan pilihan pengguna (Sinai, 2017). Sesuai dengan namanya, produk interior modular tersedia dalam bentuk modul atau bagian terpisah yang dapat ditambah ataupun dikurangi sesuai kebutuhan pengguna.

Desain modular dengan budaya kustomisasi yang memiliki manfaat yang berkelanjutan bagi pengguna karena memungkinkan untuk disesuaikan, ditingkatkan, diperbaiki, digunakan kembali dan peningkatan bertahap sebagai ganti mengganti seluruh unit, seperti konstruksi plastik LEGO yang dirancang 
pas Bersama (Spacey, 2019). Perancangan produk interior modular dapat didefinisikan sebagai proses merancang benda pada ruangan, baik pada lantai, dinding, maupun plafon yang bersifat standar dan dapat dirakit sesuai kebutuhan pengguna.

Upcycling merupakan bentuk daur ulang yang mengubah limbah menjadi bahan atau produk yang berkualitas lebih tinggi. Upcycling dilakukan untuk meningkatkan nilai dari suatu produk atau material. upcycling merupakan proses transformasi dari barang yang sudah tidak terpakai menjadi barang atau produk yang lebih berguna dengan kualitas tinggi (Sinai, 2017). Sedangkan recycle merupakan proses daur ulang dengan cara menghancurkan atau menguraikan menjadi produk material dasarnya dan membentuknya menjadi material lain.

Ergonomi berasal dari bahasa Latin yaitu ERGON (kerja) dan NOMOS (hukum alam). Ergonomi didefinisikan sebagai studi tentang aspek-aspek manusia dalam lingkungan kerjanya yang ditinjau secara anatomi, fisiologi, psikologi, engineering, manajemen dan desain perancangan (Nurmianto, 2004). Ergonomi merupakan studi terkait perilaku, sistem interaksi antara manusia, dengan pekerjaannya. Antropometri merupakan ilmu yang secara khusus mempelajari tentang pengukuran tubuh manusia untuk menentukan perbedaan pada tiap individu ataupun kelompok. Gambar 4 memperlihatkan dimensi tubuh manusia (Ching, 1996).

Istilah terakhir yang dibahas adalah kayu palet. Kayu palet merupakan kayu yang berbentuk papan yang digunakan untuk membuat alas atau tatakan dalam proses logistik dan penyimpanan barang agar tetap utuh dan memenuhi persyaratan pengiriman barang dan kemudahan penanganan barang apabila membutuhkan bantuan alat berat dalam pemindahannya.

Barang-barang kecil dikemas menggunakan crate box, sedangkan untuk barang-barang besar seperti mesin pabrik dikemas menyesuaikan ukuran barang tersebut. Untuk alas barang selama pengiriman dalam kontainer menggunakan palet dengan ukuran standar sesuai kebutuhan.

Berdasarkan ukuran dan posisi kayu pada palet, kayu palet dibagi menjadi dua tipe yaitu stringer pallet dan block pallet. Stringer pallet seperti Two Way Entry Pallet, dan Two Way Entry Pallet memiliki kerangka balok dasar memanjang sebanyak 3 yang berfungsi menahan beban barang yang berat. Dan Â BlockÂ pallet seperti Four Way Entry Pallet, dan Four Way Entry Pallet memiliki kerangka balok dasar pada titik-titik tertentu yang berfungsi menahan beban barang yang ringan (Safitri \& Rachmat, 2016).
Kayu palet yang digunakan untuk ekspor dan impor barang, memiliki regulasi sendiri seperti yang telah ditetapkan oleh IPPC / International Plant Protection Convention yaitu sertifikasi International Standard of Phytosanitary Measures No.15 (\#ISPM15). Untuk mencapai sertifikasi tersebut, kayu palet harus diberi perlakuan: Debarked (DB), Heat Treatment (HT), Dielectric Heating (DH), Methyl Bromide Treatment (MB). Jika kayu palet sudah tersertifikasi, dapat dipastikan bahwa kayu tersebut ramah lingkungan, tanpa kulit, tahan rayap dan jamur, tidak mudah rusak dan patah (Southampton Freight Services Ltd, 2012).

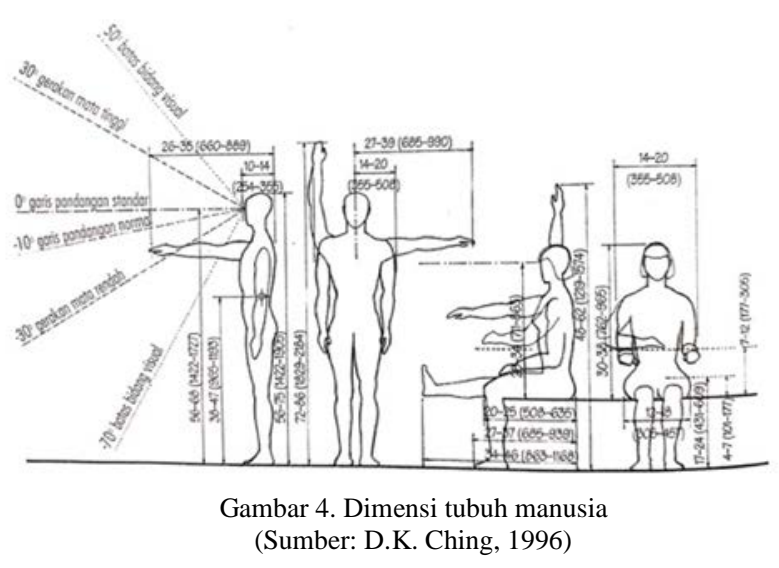

Gambar \& Ukuran Pallet Standard
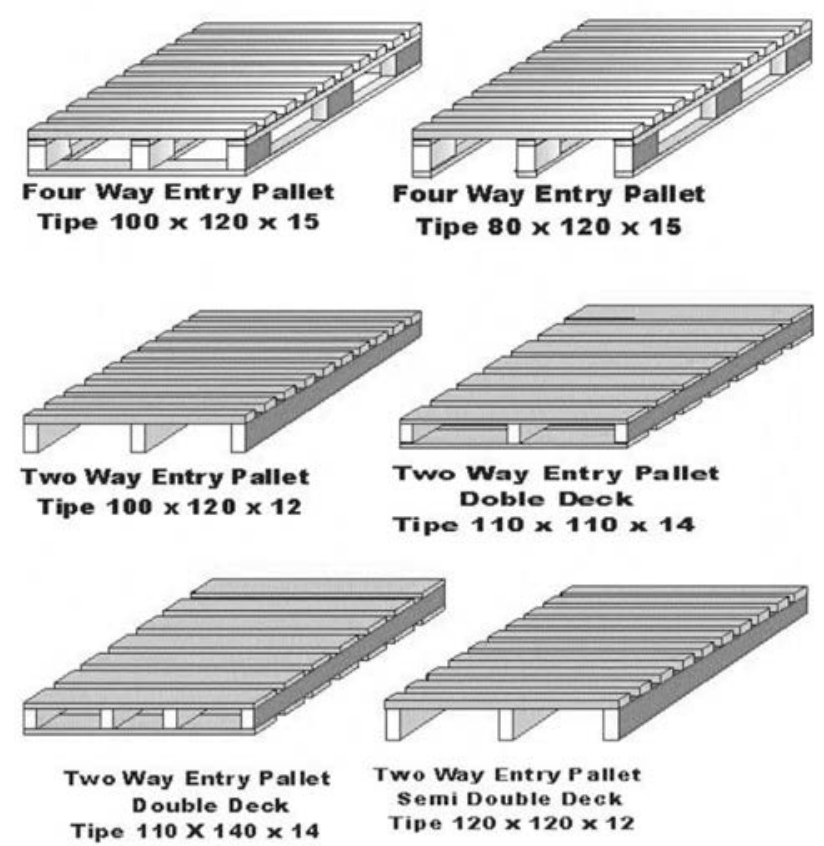

Gambar 5. Jenis dan ukuran palet standar (Sumber: Safitiri \& Rachmat, 2016) 


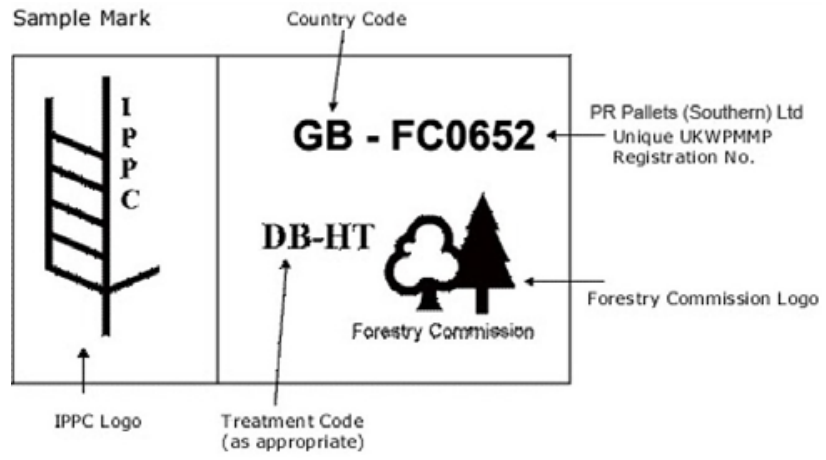

Gambar 6. Kode \#ISPM15 pada kayu palet lolos uji (Sumber: Southampton Freight Services Ltd, 2012)

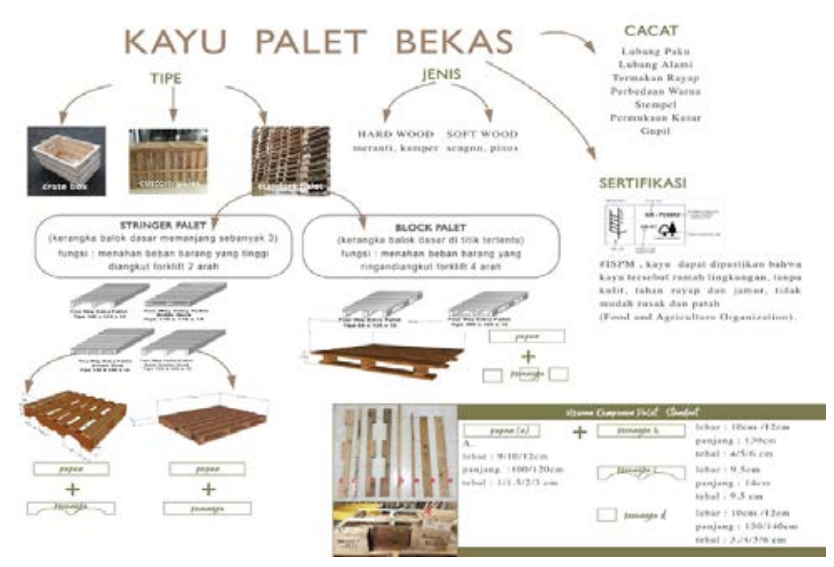

Gambar 7. Analisis kayu palet bekas

\section{KAYU BEKAS PALET PINUS}
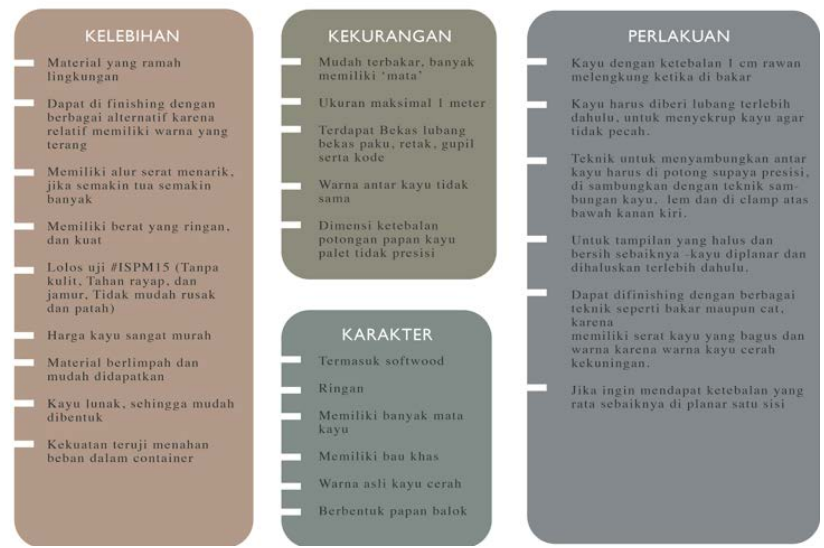

Gambar 8. Analisis kelebihan, kekurangan, karakter, pelakuan pada kayu palet
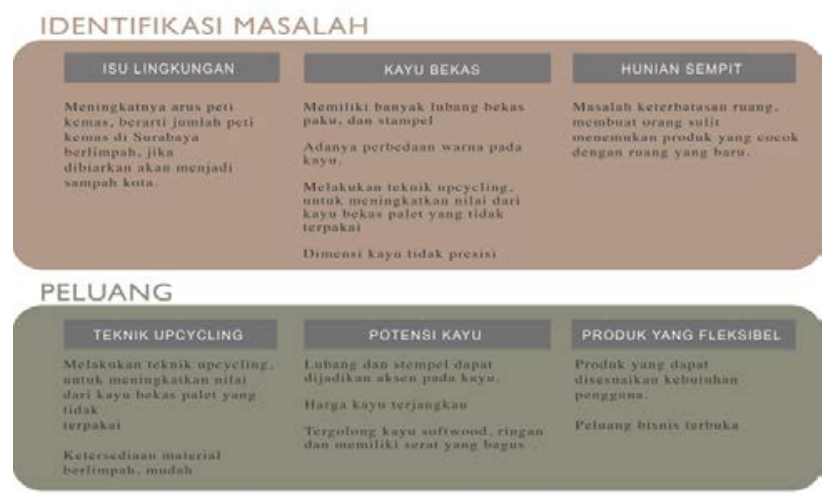

Produk Interior Modular dengan Upcycling Kayu Bekas Palet

ECO FRIENDLY SIMPLE MODULAR

$$
\text { eco-lego }
$$

Gambar 9. Identifikasi masalah, peluang, dan konsep desain

\section{Hasil dan Pembahasan}

Berdasarkan hasil survei, stringer pallet memiliki ketersediaan yang lebih banyak dari pada block palet. Kerangka balok pada block palet terbentuk dari serat kayu press sehingga banyak yang rusak, dan ukurannya relatif sangat kecil. Kerangka pada stringer pallet terdapat dua macam, bentuk bilah utuh dan yang berbentuk huruf "W". Bentuk "W" pada kerangka ini cenderung dibuang karena bentuknya. Maka dari itu pada perancangan ini akan menggunakan stringer pallet dengan kerangka "W". Dari hasil analisis tersebut akan dirumuskan dalam bentuk mind mapping programmatic concept. Beserta analisis kelebihan, kekurangan, karakter, dan perlakuan kayu (Gambar 8).
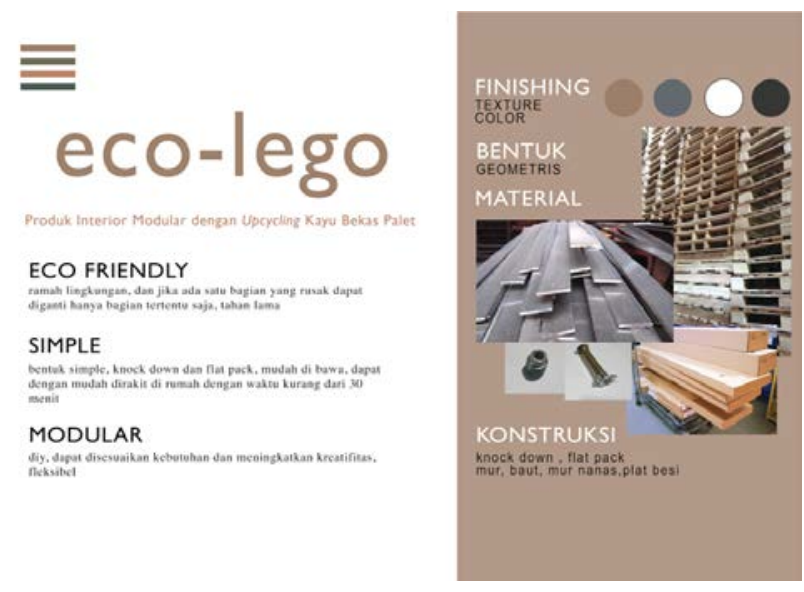

Gambar 10. Konsep desain Eco Lego 


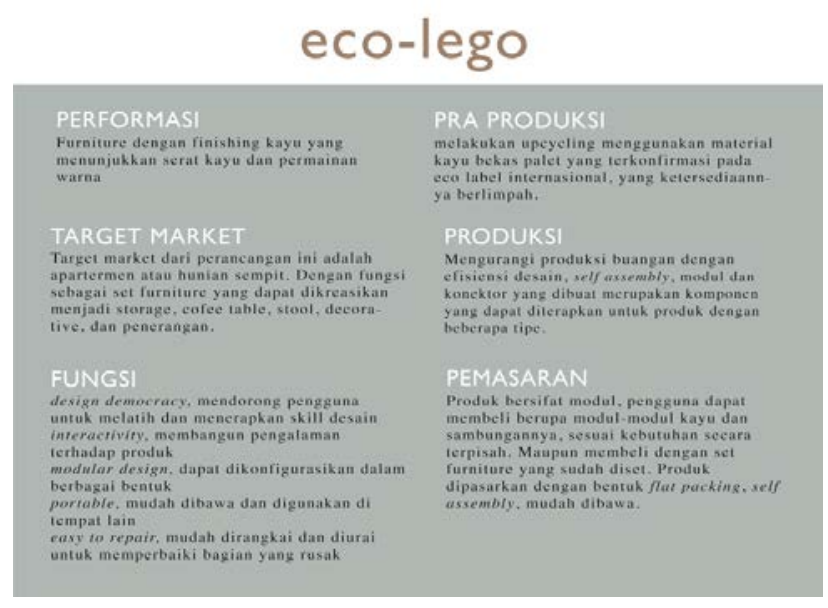

Gambar 11. Strategi Eco Lego

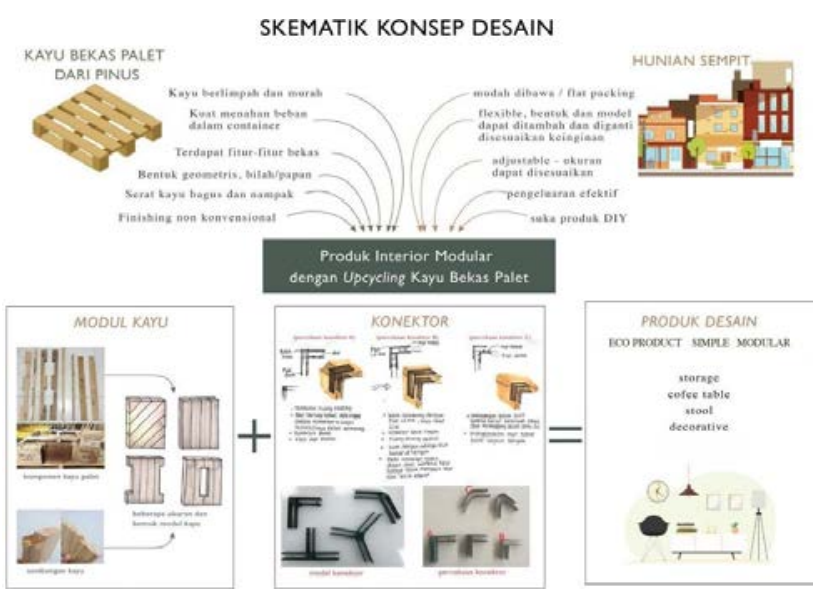

Gambar 12. Skematik konsep desain

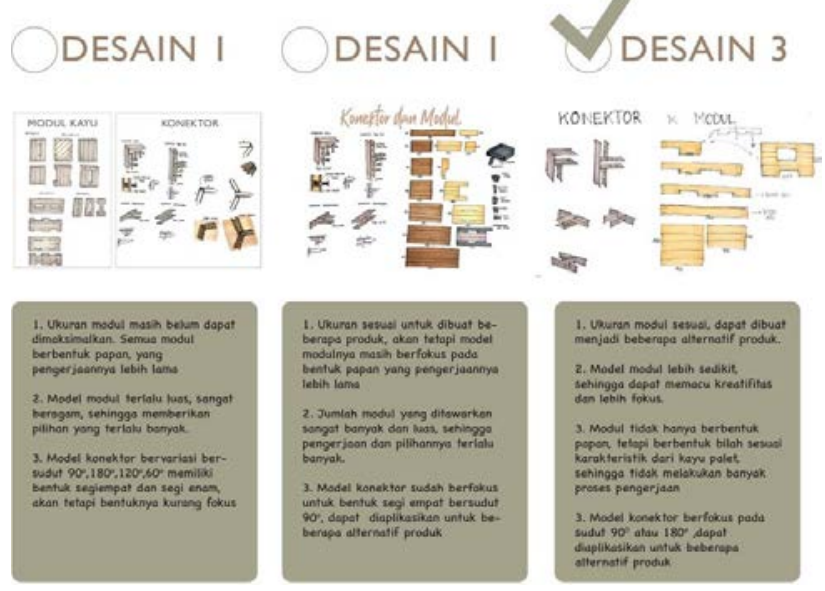

Gambar 13. Analisis transformasi desain

\section{三 KONEKTOR \& MODUL}

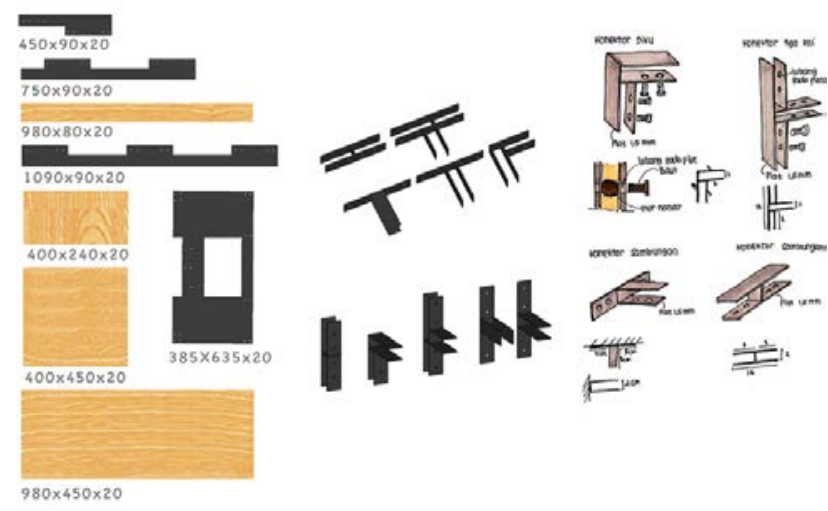

Gambar 14. Konektor dan modul COGO

\section{Design Concept}

Melihat potensi dari kayu bekas palet maka akan dilakukan upcycling untuk menjadi produk yang fleksibel. Maka dari itu konsep dari perancangan
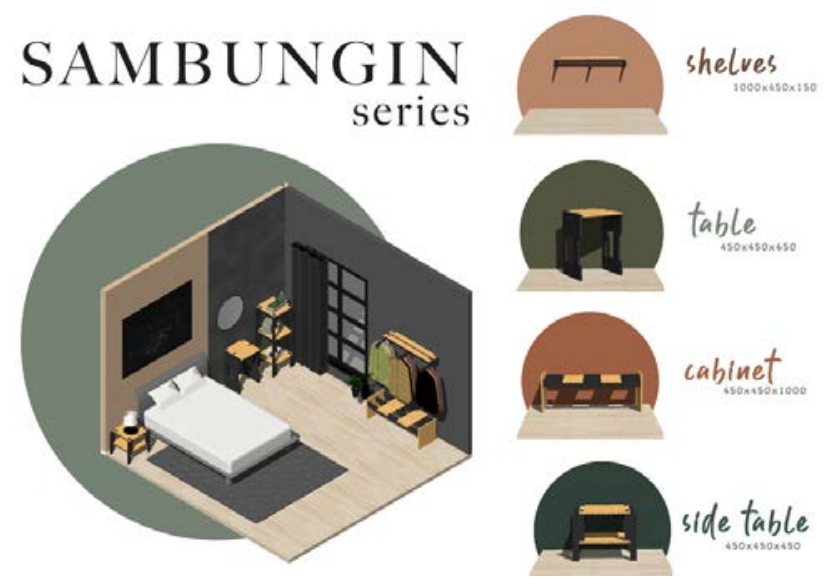

Gambar 15. Sambungin Series
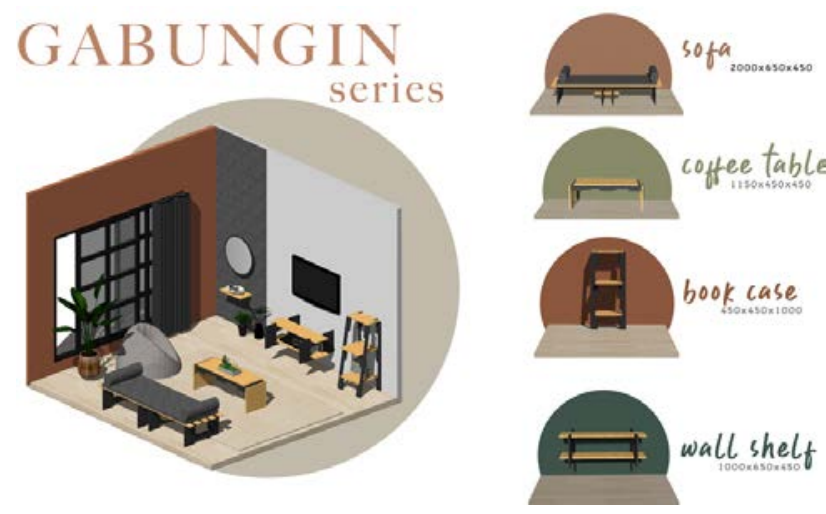

Gambar 16. Gabungin Series 

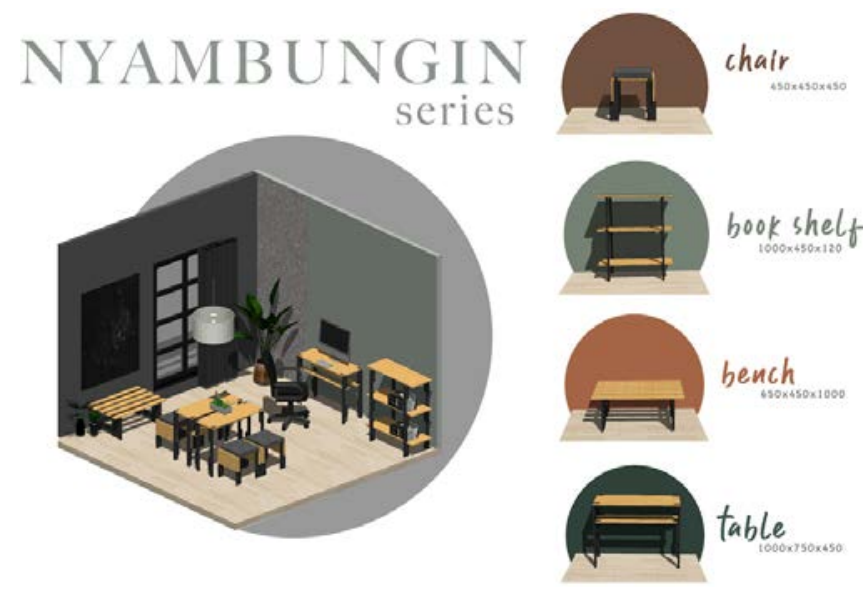

Gambar 17. Nyambungin Series

produk interior modular dengan upcycling kayu bekas palet ini akan menggunakan konsep desain eco lego, sesuai namanya produk yang diharapkan adalah produk yang eco friendly, juga mengambil konsep dari mainan lego yang simple, modular.

\section{Transformasi Pengembangan Desain}

Dari hasil analisis transformasi desain, maka perancangan ini menggunakan desain 3 untuk direalisasikan, meskipun jumlah modulnya paling sedikit tetapi hasilnya tetap bisa maksimal. Modul terdiri dari dua macam bentuk yaitu papan dan bilah, bentuk bilah sesuai dengan karakteristik kayu bekas palet sehingga memudahkan proses produksi. Desain yang terpilih ini karena dari konektor dan modul yang minimal, dapat membentuk produk dengan jumlah yang maksimal

Desain akhir dari perancangan produk interior modular dengan upcycling kayu bekas palet ini disesuaikan dengan karakteristik dari kayu bekas palet. Kayu bekas palet yang digunakan pada perancangan ini yaitu stringer pallet karena ketersediaannya berlimpah dan murah. Jenis kayu yang digunakan yaitu kayu kayu pinus, dengan karakter serat kayu yang bagus sehingga bisa difinishing non-konvensional, memiliki fitur bekas seperti lubang bekas paku dan stempel yang dapat menjadi aksen pada kayu, merupakan kayu softwood, ringan, dan berbentuk bilah-bilah.

Produk yang direalisasikan merupakan modul dan konektor yang mewakili 3 set produk tersebut. Dari modul dan konektor yang mewakili tersebut dapat di lepas pasang untuk menunjukkan bentuk dari produk pada 3 series tersebut. Sehingga dapat melihat bentukan dari masing masing produk. Untuk itu modul dan konektor di-finishing agar cocok untuk di aplikasikan ke semua produk tersebut. Proses
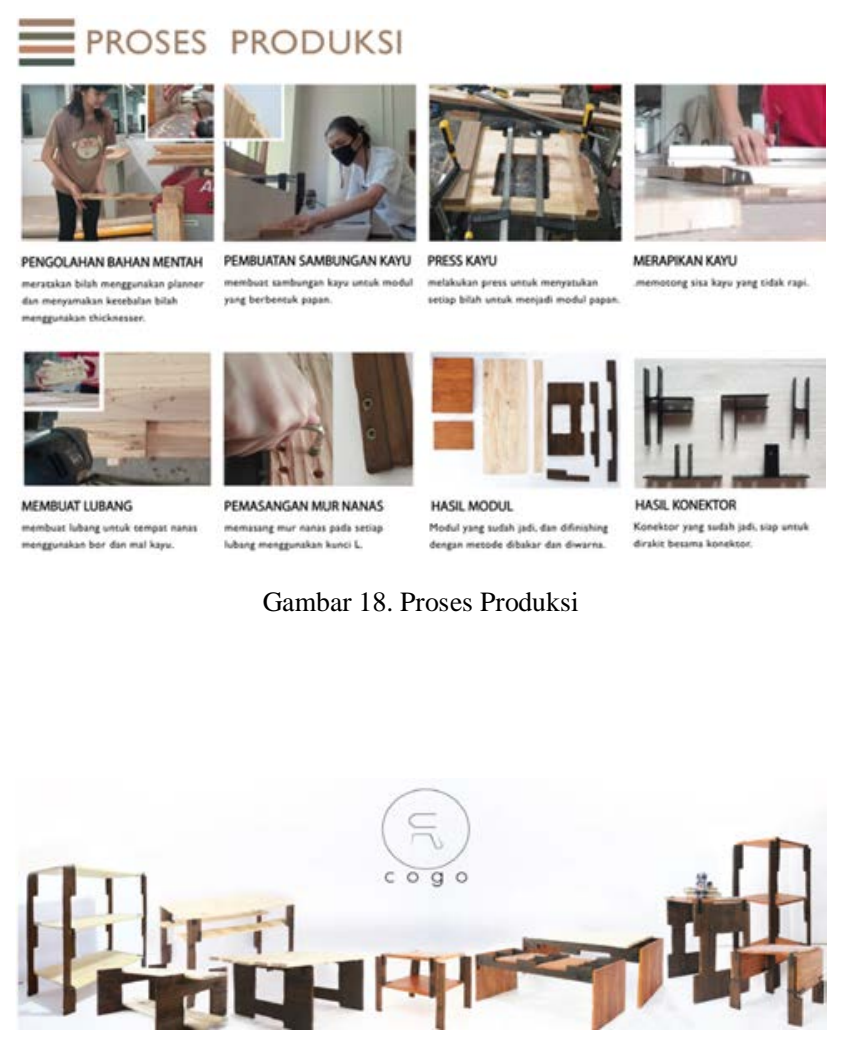

Gambar 19. Dokumentasi produk keseluruhan

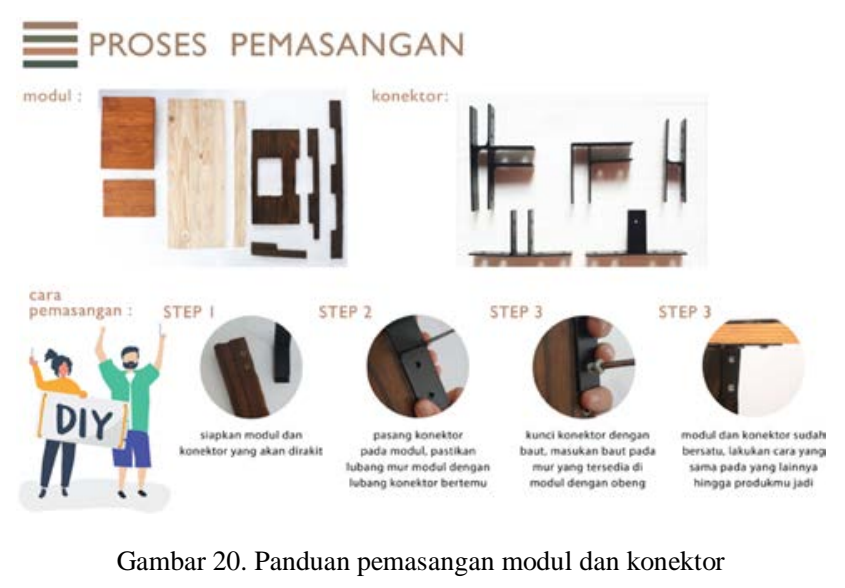

pembuatan modul dilakukan secara mandiri di lab kayu milik Program Studi Desain Interior, Fakultas Seni dan Desain, Universitas Kristen Petra Surabaya. Karena jenis modul tidak banyak dan bentuk modul berdasarkan karakteristik dari kayu bekas palet, maka proses produksinya mudah dan cepat. Pembuatan konektor tidak dilakukan sendiri, tetapi diserahkan pada tukang las. 


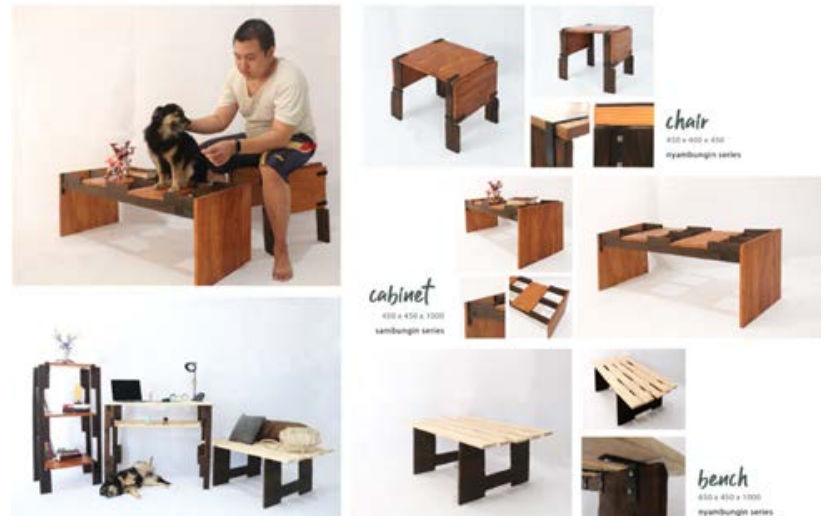

Gambar 21. Dokumentasi produk

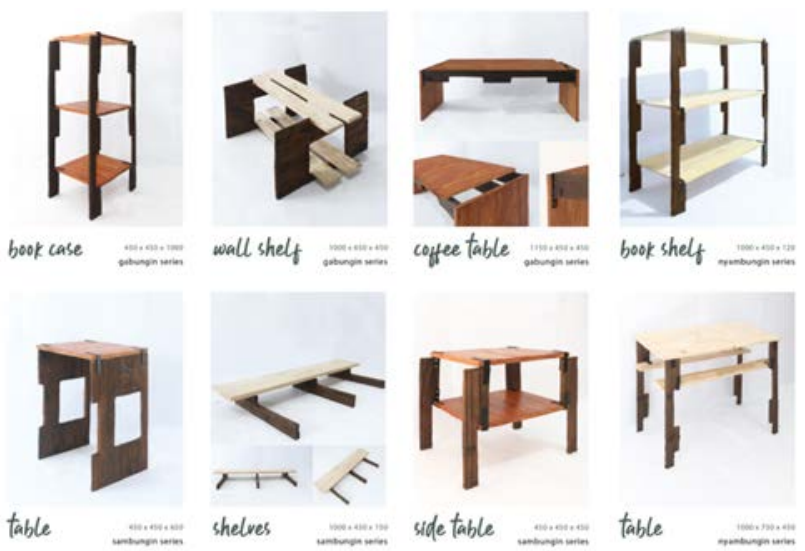

Gambar 22. Dokumentasi produk

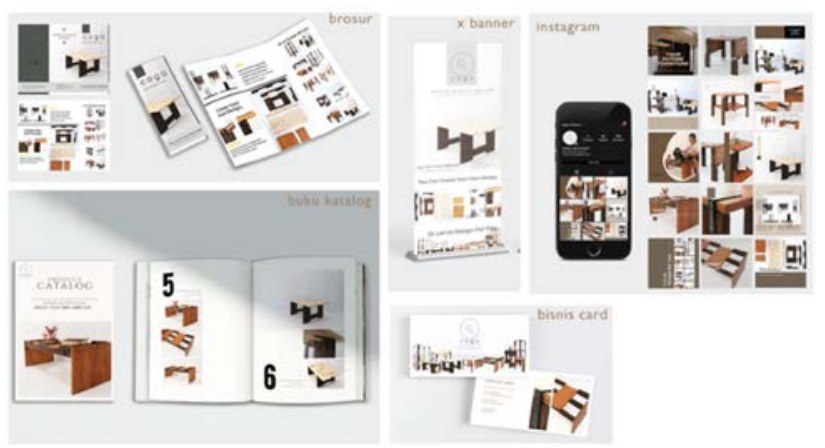

Gambar 23. Media promosi COGO

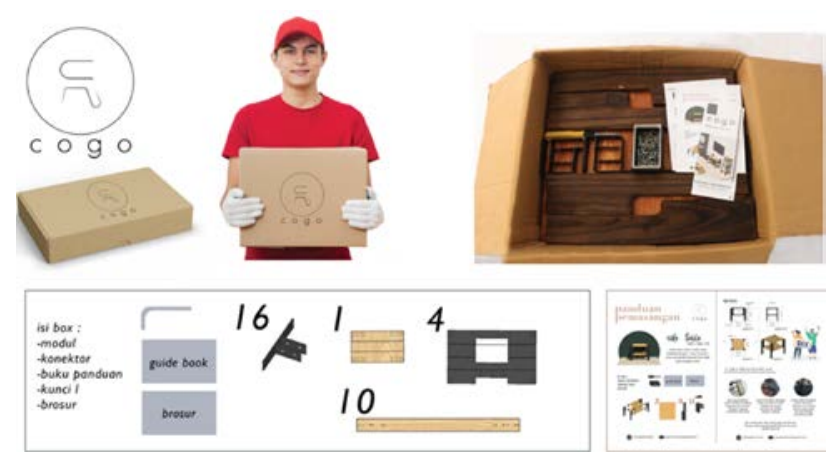

Gambar 24. Packaging dan isi box COGO
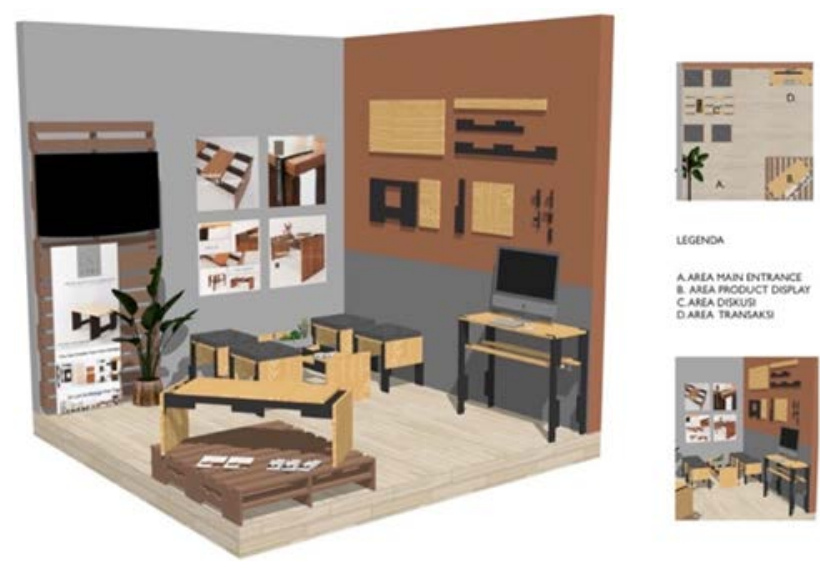

Gambar 25. Desain Booth 1
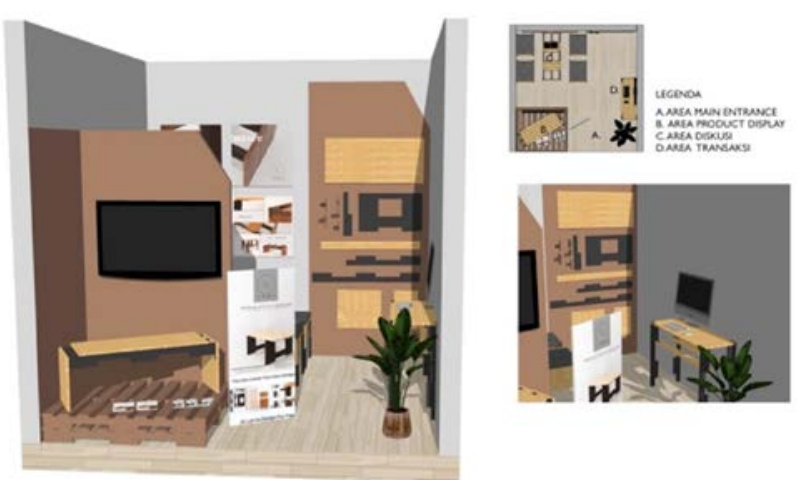

Gambar 26. Desain Booth 2

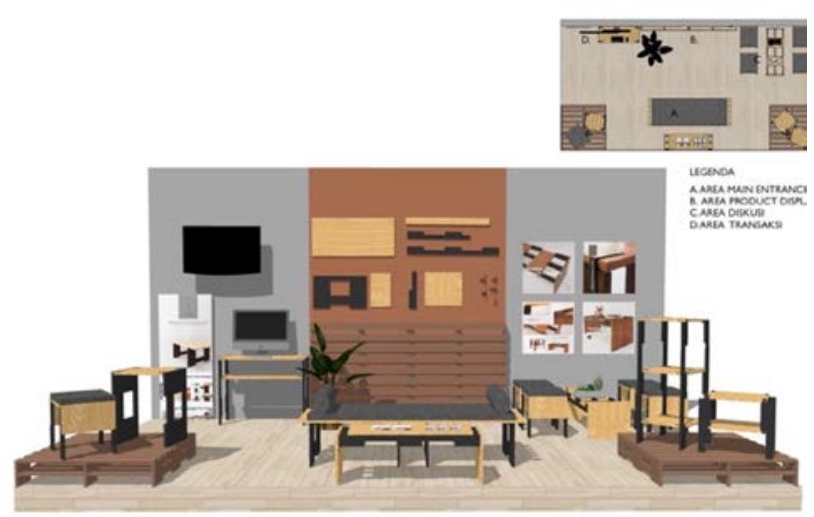

Gambar 27. Desain Booth 3

Produk COGO akan dipasarkan secara online, untuk itu membutuhkan packaging untuk pengiriman barang. Karena produk COGO ini self assembling maka dalam packagingnya akan disediakan alat untuk memudahkan pemasangan, seperti buku panduan, obeng, baut, dan brosur (Gambar 24). Selain itu, untuk mengenalkan produk COGO dilakukan promosi dengan cara mengikuti event-event. Untuk itu dibuat beberapa alternatif desain booth (Gambar 25-27). 
Sesuai konsepnya, produk interior modular dengan upcycling kayu bekas palet ini memiliki brand yaitu COGO, "co" dari kata eco dan "go" dari kata lego. Logo COGO berbentuk illustrasi stringer pallet dan furniture yang menjadi ciri khas dari produk COGO. Selain itu juga dibuat beberapa media promosi untuk mendukung brand COGO ini, seperti kartu nama, brosur, $x$-banner, buku katalog, dan Instagram (Gambar 23).

\section{Test dan Review Produk}

Setelah produk interior modular dari kayu bekas palet ini jadi, dilakukan test untuk menguji kekuatan dan fungsi produk. Produk dicoba diduduki oleh pria dengan tinggi $180 \mathrm{~cm}$ berat $101 \mathrm{~kg}$, produk ke dua dicoba diduduki oleh pria dengan berat badan $101 \mathrm{~kg}$ dan wanita dengan berat badan $54 \mathrm{~kg}$, dan produk meja coba diduduki oleh anjing dengan berat badan.

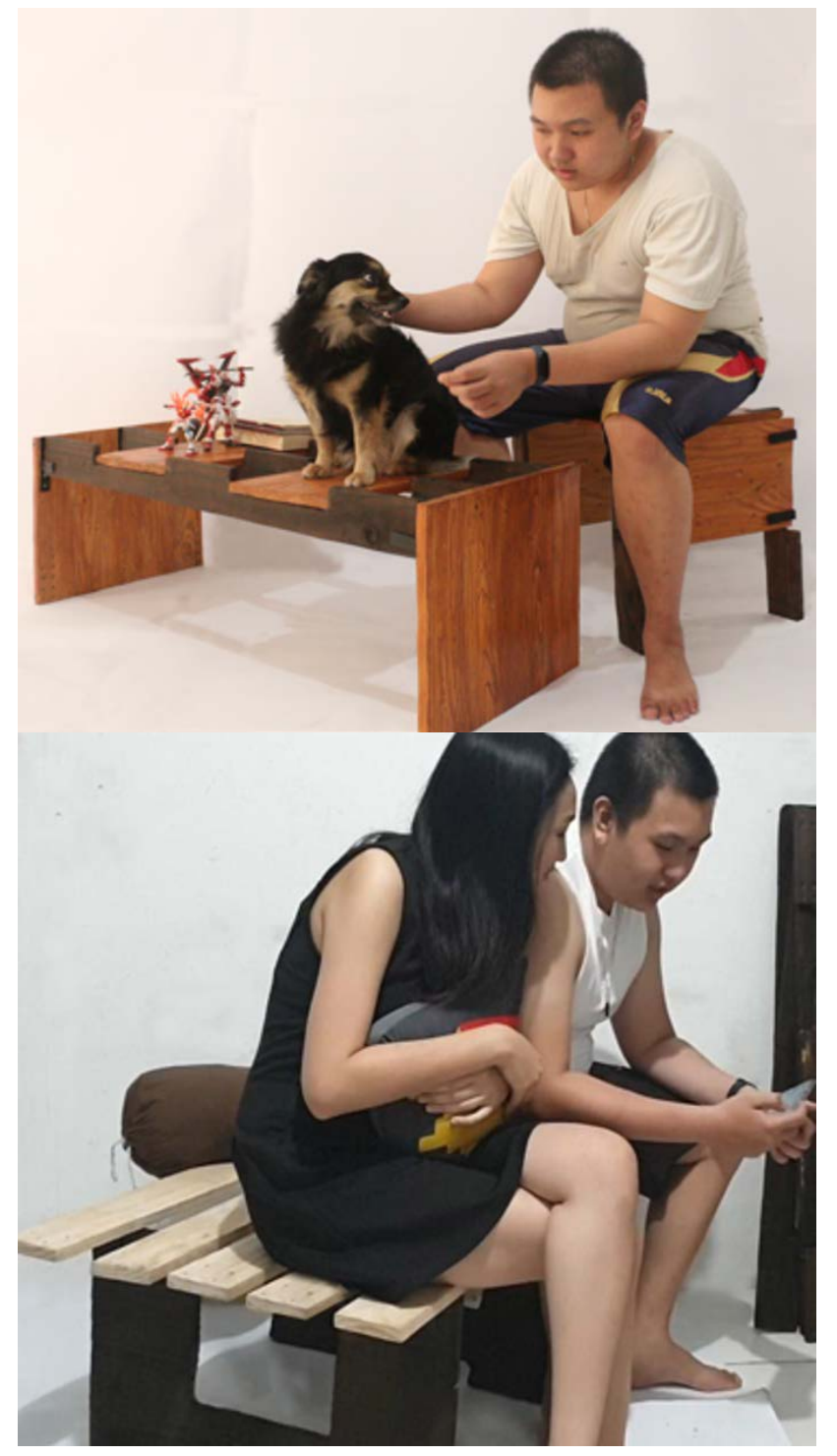

Gambar 28. Test Produk
Dan didapatkan hasil bahwa produk interior modular dari kayu bekas palet ini berfungsi dan kuat.

Dilakukan produk review untuk mendapatkan feedback kepada beberapa orang dengan cara menunjukkan produk melalui media sosial, katalog produk, dan Youtube dari COGO. Feedback yang didapat tentang produk ini yaitu unik, kayu bekas palet di-upcycling menjadi produk interior modular yang dapat disesuaikan dengan kebutuhan, mudah dirakit, tidak ribet, dan ekonomis. Menurut penulis, produk ini dapat dikembangkan dari model konektor yang dibuat lebih rapi dengan metode yang lain. Dan untuk kerapian dalam proses produksi dapat ditingkatkan sehingga hasil yang diperoleh lebih maximal.

\section{Kesimpulan}

Pemahaman akan karakter dan potensi kayu bekas palet dibutuhkan untuk menerapkan prinsip upcycling. Karakter kayu bekas palet itu sendiri dapat menjadi potensi. Seperti ketersediaannya yang berlimpah dan murah dapat membuat harganya terjangkau. Selain itu memiliki warna serat yang menarik sehingga dapat difinishing non konvensional yang menonjolkan serat kayu. Kayunya lunak dan ringan yang memudahkan proses produksi dan distribusi, memiliki bentuk bilah dan kerangka "W" yang dapat menjadi ciri khas dari produk. Dan memiliki fitus kebekasan seperti mata kayu, lubang, retak dan gupil, yang dapat di-ekspos dan menjadi nilai tambah.

Dengan pemahaman akan karakter dan potensi kayu bekas palet, maka dilakukan perancangan produk interior modular dengan bentuk modul dan bilah. Bentuk modul yang ditawarkan berasal dari karakteristik bentuk dan ukuran material, sehingga modul yang dihasilkan tidak menghasilkan banyak buangan atau limbah produksi. Modul dapat dirakit menggunakan sambungan konektor menjadi 12 macam produk dan dapat dikreasikan menjadi berbagai macam produk sesuai kebutuhan dan keinginan pengguna.

Produk interior modular dengan upcycling kayu bekas palet ini di-branding dengan nama COGO, yang berasal dari kata co yang artinya eco, dan go yang artinya lego. Sesuai namanya produk ini merupakan ecoproduct yang memberikan kebebasan desain untuk penggunanya seperti lego. Tetapi produk COGO juga menawarkan self assembly, easy to repair, portable, interactivity yang yang akan dipromosikan menggunakan media digital dan non digital. 


\section{Ucapan Terima Kasih}

Penelitian terapan ini adalah bagian dari "ServiceLearning and Design Thinking in Solid Waste Recycling and Reuse Projects” yang didanai oleh United Board for Christian Higher Education in Asia. Atas subsidi pendanaan dalam pelaksanaan penelitian ini disampaikan terimakasih.

\section{Daftar Pustaka}

Antonius, I. (2019). Arus Petikemas di Tanjung Perak Surabaya Tembus Target. Retrieved from https://surabaya.liputan6.com/read/4075510/arus-petikemasdi-tanjung-peak-surabaya-tembus-target

Arya PN, N., Azhar, H., Reza, A., Pratama, M. R., \& Nugraha, M. I. (2020). Mengolah material limbah menjadi smart wall light. In Prosiding SNADES 2020 - Optimisme Desain Untuk Pembangunan Negeri. Retrieved from http://repository.upnjatim.ac.id/1214/1/08 PROSIDING SNADES $2020 \% 2850-55 \% 29 . p d f$

Beatrice, A. E., Setiadi, S., Saraswati, D. K., \& MT, S. S. (2018). Pemanfaatan Limbah Kayu Peti Kemas Sebagai Bahan Dasar Perancangan Aksesoris Interior Pengembangan Metodologi Penciptaan Seni Rupa dan Desain. In Seminar Nasional Seni dan Desain 2018 (pp. 57-63). State University of Surabaya.

Ching, F. D. (1996). Ilustrasi Desain Interior. Jakarta: Penerbit
Erlangga.

Juanda, A. (2019). Tiga Saran Arsitek dalam Menata Rumah Mungil agar Tidak Terasa Sempit. Retrieved from https://idea.grid.id/read/091758801/tiga-saran-arsitek-dalammenata-rumah-mungil-agar-tidak-terasa-sempit?page=all

Kania, D. (2018). Apartemen Tetap Lapang dengan Smart Furniture. Retrieved from https://www.dekoruma.com/artikel/68120/apartemen-tetaplapang-dengan-smart-furniture

Nurmianto, E. (2004). Ergonomi konsep dasar dan aplikasinya (Edisi 2). Surabaya: Guna Widya.

Prasetya, R. D. (2016). Potensi Limbah Kayu Industri Mebel untuk Produk Home Accessories. PRODUCTUM Jurnal Desain Produk (Pengetahuan Dan Perancangan Produk), 1(1), 39-51.

Ririn, I. (2017). Case Furnitur Modular untuk Hunian Modern.

Safitri, R., \& Rachmat, G. (2016). Studi Kelayakan Kayu Bekas Landasan Peti Kemas sebagai Elemen Interior Lepas. ATRAT: Jurnal Seni Rupa, 4(3), 243-252.

Sinai, M. (2017). Upcycling vs Recycling. Retrieved from https://recyclenation.com/2017/02/upcycling-vs-recycling/

Southampton Freight Services Ltd. (2012). ISPM15 Ocean Freight (FCL) Packing Declaration. Retrieved from https://www.sotonfreight.co.uk/information-centre/ispm15wood-packing-declaration

Spacey, J. (2019). What is Modular Design. Retrieved from https://simplicable.com/new/modular-design 